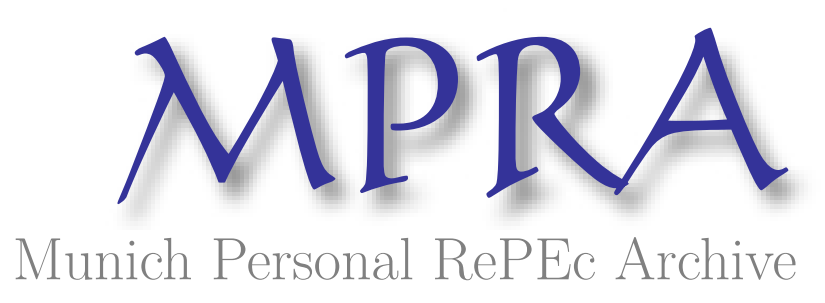

\title{
Optimal exchange rate policy in a low interest rate environment
}

Pavasuthipaisit, Robert

Princeton University

May 2007

Online at https://mpra.ub.uni-muenchen.de/3596/

MPRA Paper No. 3596, posted 16 Jun 2007 UTC 


\title{
Optimal Exchange Rate Policy in a Low Interest Rate Environment
}

\author{
Robert Pavasuthipaisit ${ }^{a, *}$ \\ ${ }^{a}$ Princeton University, USA
}

May 2007

\begin{abstract}
This paper examines optimal exchange policy when nominal interest rates are unusually low, as experienced by several Asian economies and Japan since July 2006. The paper finds that in such environments, it is optimal to create a nominal depreciation to offset contractionary disturbances. However, the limited scope of monetary policy easing may compromise the ability of the central bank to create a nominal depreciation especially if the central bank makes decisions on monetary policy making on a discretionary basis. In order to successfully create a nominal depreciation, the central bank needs to rely on the expectations channel, by making a credible promise to keep its currency weak going forward. Finally, trade liberalization, by enhancing the role of the exchange rate channel on the transmission mechanism, may allow the central bank to achieve lower average inflation.
\end{abstract}

JEL Classification: E52, F41, F42

Keywords: Zero lower bound, liquidity trap, exchange rate policy, open-economy macroeconomics.

\footnotetext{
${ }^{*}$ Correspondence: Department of Economics, 001 Fisher Hall, Princeton NJ, 08544, USA, tel.: (609) 430-4638, fax: (609) 258-6419, email: rpavasut@princeton.edu, homepage: http://www.princeton.edu/ rpavasut.
} 


\section{Introduction}

The recent experience of low interest rates in many countries has led to considerable interest in the design of monetary policy in the presence of a zero lower bound on nominal interest rates. Such a low interest rate environment presents a particular problem for monetary policy since the effectiveness of short-term nominal interest rates, a main instrument for most central banks, could be limited by the zero lower bound. Particularly, the central bank will not be able to offset severe contractionary disturbances by lowering the nominal interest rate by the desired amount. Thus, the central bank will not be able to stimulate the economy via the standard interest-rate channel.

Academics and policymakers alike have made proposals regarding the conduct of monetary policy in the presence of such a constraint. One interesting approach that has been widely studied is for the central bank to resort to the exchange rate channel and use exchange rates as a policy instrument, if the interest-rate channel becomes ineffective due to the zero lower bound. Prominent studies based on this approach include Orphanides and Wieland (2000), Svensson (2001), McCallum (2002) and Coenen and Wieland (2003, 2004). In a broader context, this is also related to a growing literature in which many authors have emphasized the importance of exchange rates as a distinct policy instrument in managing aggregate demand. ${ }^{1}$

This is indeed the strategy pursued by many real-world central banks, the most interesting of which are those in the Far East. Having experienced one of the lowest short-term nominal interests since 2000, several Asian central banks have actively pursued several measures to influence their exchange rates. ${ }^{2}$ Even so, it appears that these central banks, especially those under floating exchange rates, have failed to achieve exchange rates that are deemed to be appropriate for their economic conditions. This raises a question whether such exchange rate policy is desirable, especially if the attempt to achieve the target exchange rates leads to a conflict with other policy objectives. And in the case that such policy is indeed desirable, what is the implementation strategy that will allow central banks to achieve their target exchange rates?

This paper sets forth a framework to study optimal exchange rate policy when the nominal interest rate is low and is likely to be constrained by the zero lower bound. In particular, the paper characterizes the path of the nominal exchange rate that is consistent with the commitment equilibrium, an optimal allocation that can be implemented by inflation targeting (Svensson and Woodford, 2005).

This paper differs from the earlier literature in some important aspects. First of all, due to computational difficulties in solving a fully dynamic model with an explicit bound, which is essentially a nonlinear setup, the earlier literature has made certain assumptions that are unusual for modern dynamic

\footnotetext{
${ }^{1}$ See for example Taylor (2001), Edwards and Yeyati (2005) and Edwards (2006).

${ }^{2}$ Section 7 discusses the recent experience of a few Asian central banks that attempted to 'manipulate' their exchange rates.
} 
stochastic general equilibrium (DSGE) models, in order to simplify the computation. These include working on a simplified setup that is not fully dynamic or assuming away the standard conditions of uncertainty and rational expectations. ${ }^{3}$ This setup appears to be useful in studying how the central bank should respond when the nominal interest rate has already been constrained at zero for some time, the scenario that is applicable to the economic experience of Japan prior to 2006.

This paper, on the other hand, relies on a microfounded open-economy DSGE model, with the standard conditions of uncertainty and rational expectations. Using this setup allows us to study monetary policy strategy in which the nominal interest rate is low, but strictly above zero, and there is a possibility that the nominal interest rate might fall to zero, if the economy is hit by severe contractionary shocks. This is the scenario that is currently relevant to Japan and several Asian countries.

Furthermore, in contrast to earlier papers, most of which rely on Taylortype monetary policy rules, this paper studies "optimal monetary policy" in the sense that the central bank sets the nominal interest rate to strike an optimal balance between the costs of variability in inflation and the costs of variability in the output gap.

Thus, this paper is closely related to Adam and Billi (2006, 2007) who study optimal monetary policy in the presence of the zero lower bound but in a closedeconomy model. It should be noted that extending the analysis of Adam and Billi into the open-economy setting is not straightforward. For one thing, with the standard assumptions of uncertainty and rational expectations, there exists no closed-form solution to the problem of optimal monetary policy under nonlinear models. To solve such problems, one has to resort to numerical analysis, and specifically in this case, the collocation method.

Like most algorithms in numerical analysis, a drawback of the collocation method is that the method may not work when applied to a model larger than the canonical closed-economy DSGE model. This is known as the curse of dimensionality, a situation in which numerical-analysis algorithms fail when applied to a large system of equations. As a contribution to the literature, this paper presents a strategy to avoid the curse of dimensionality when applying the collocation method to multi-sector models, such as an open-economy DSGE model.

This paper derives three main results. First, when interest rates are low, it is optimal for the central bank to engineer a nominal depreciation of its currency in response to a contractionary shock.

\footnotetext{
${ }^{3}$ For example, McCallum (2002) does not explicitly recognize the zero lower bound, but starts from the scenario in which the nominal interest rate has been constrained at zero. Therefore, the nominal interest rate is fixed at zero and the uncovered interest parity is dropped from the model. Svensson (2004) does not rely on the New Keynesian Phillip curve but instead assumes that firms set prices one period in advance and solve a three-period model in which the natural interest rate turns negative during period 2. Coenen and Wieland (2003) work on a fully dynamic model, but assume that certainty equivalence counterfactually holds. This implies that private agents form expectations on the future paths of the economy as if the zero lower bound did not exist.
} 
Second, in the context of floating exchange rates, which become prevalent in both industrialized and emerging-market countries, the central bank cannot control exchange rates perfectly. Therefore the central bank may not necessarily be able to achieve a nominal depreciation at will. However, this paper finds that adopting commitment-based policy, by making a credible promise that constrains the central bank's action in certain ways, will allow the nominal exchange rate to depreciate in response to a negative demand shock.

Finally, in a low interest rate environment, the exchange rate channel can play a key role in the management of aggregate demand. This paper finds that the more open the economy is, the lower average inflation it can achieve. A policy implication is that trade liberalization, especially among emergingmarket economies, can improve the stabilization performance of monetary policy regimes in these countries.

The remainder of the paper proceeds in the following manner. Section 2 sets up the model used for the analysis. Section 3 discusses the curse of dimensionality when applying the collocation method to an open economy model and presents a method to derive the optimal path of the nominal exchange rate. Section 4 investigates the effect of the zero lower bound on the optimal target rate of inflation and the stabilization performance of monetary policy. Section 5 characterizes the optimal paths of the nominal exchange rate under commitment policy and discretionary policy. In section 6 , the importance of the exchange rate channel in the low interest rate environment is examined. Section 7 discusses some stylized facts to which the analysis in this paper may be applicable. Section 8 concludes.

\section{The model economy}

The model extends the work of Svensson (2004), by introducing a staggered price-setting strategy into the model of two economies, home and foreign. The home country is assumed to have a continuum of identical home households $h$ $(0 \leq h \leq 1-\alpha)$ while the foreign country has a continuum of identical foreign households $h^{*}\left(1-\alpha \leq h^{*} \leq 1\right)$. Households in the home country consume a basket of final home goods and final foreign (imported) goods. The same is true for households in the foreign country, who consume a basket of final foreign goods and final home (imported) goods.

Home and foreign final goods are produced in two stages. In the second stage, production of home and foreign final goods occurs under perfect competition with a continuum of nontraded intermediate inputs of local differentiated intermediate goods. In the first stage, a continuum of monopolistically competitive home and foreign firms produce differentiated intermediate goods.

In this section, I present a log-linearized version of the aggregate relationships of the model. The basic setups of the model, including households' preferences and constraints, the specification of the aggregate index of differentiated 
intermediate goods, and the staggered price setting, are the same as a typical open-economy DSGE model.

Throughout, $z_{t}$ denotes $\log Z_{t}-\log Z$ where $Z_{t}$ is a variable and $Z$ is its steady state. $\widetilde{z}_{t}$ denotes $\log Z_{t}{ }^{4}$ Prices and quantities in the foreign country are denoted with an asterisk Greek and Roman letters denote fixed parameters.

\subsection{Households}

Home households supply labor to firms, save in one-period riskless bonds and consume a basket of domestic goods and imported goods. Home households choose consumption, savings and labor supply to maximize intertemporal utility subject to a budget constraint. Solving the households optimization problem yields standard first-order conditions for consumption/savings and labor supply;

$$
\begin{gathered}
w_{t}-p_{t}^{c}=\varphi n_{t}+\frac{1}{\sigma} c_{t} \\
c_{t}=\mathrm{E}_{t} c_{t+1}-\sigma\left(i_{t}-\mathrm{E}_{t} \pi_{t+1}^{c}-\rho\right)
\end{gathered}
$$

where $w_{t}$ is the nominal wage in period $t ; n_{t}$ is the household's supply of labor; $c_{t}$ is the household's consumption; $i_{t}$ is the nominal interest rate; $\varphi>0$ is the elasticity of the marginal disutility of labor with respect to labor supply; $\sigma>0$ is the intertemporal elasticity of substitution in consumption; $\rho$ is the constant rate of time preference; and $\mathrm{E}_{t}$ denotes expectations conditional on information available in period $t . \pi_{t}^{c} \equiv p_{t}^{c}-p_{t-1}^{c}$ is CPI-inflation. $\quad p_{t}^{c}$ is the CPI which is given by

$$
p_{t}^{c}=(1-\alpha) p_{t}+\alpha p_{t}^{f}=p_{t}+\alpha \tau_{t}
$$

where $\tau_{t} \equiv p_{t}^{f}-p_{t}$ is the term of trade; $p_{t}^{f}$ and $p_{t}$ denote the home-currency prices of foreign and home goods, respectively. It follows that

$$
\pi_{t}^{c}=\pi_{t}+\alpha\left(\tau_{t}-\tau_{t-1}\right)
$$

\subsection{Foreign households, international linkage and aggre- gate demand determination}

The foreign CPI fulfills

$$
p_{t}^{c *}=\alpha p_{t}^{*}+(1-\alpha) p_{t}^{h *}
$$

Assume that prices are set in the currency of the producer and exchange-rate pass-through is perfect, the Laws of One Price hold

\footnotetext{
${ }^{4}$ Except $i_{t}$ which is the continuously compounded nominal interest rate and $\bar{r}_{t}$, which is the natural interest rate.
} 


$$
\begin{gathered}
p_{t}^{f}=p_{t}^{*}+s_{t} \\
p_{t}^{h *}=p_{t}-s_{t}
\end{gathered}
$$

where $s_{t}$ is the $(\log )$ exchange rate.

Thus, we can write the (log-linearized) foreign CPI as

$$
p_{t}^{c *}=\alpha p_{t}^{*}+(1-\alpha)\left(p_{t}-s_{t}\right)=p_{t}^{*}-(1-\alpha) \tau_{t}
$$

It follows that purchasing power parity (PPP) holds,

$$
p_{t}^{c}=p_{t}^{c *}+s_{t}
$$

Using (3) and (7) in (8),

$$
\begin{aligned}
& p_{t}=p_{t}^{*}+s_{t}-\tau_{t} \\
& \pi_{t}=\pi_{t}^{*}+s_{t}-s_{t-1}-\tau_{t}+\tau_{t-1}
\end{aligned}
$$

Under the assumption of complete international financial markets, the expected rate of nominal depreciation is related to the difference between the home and the foreign nominal interest rates according to an uncovered interest parity

$$
i_{t}=i_{t}^{*}+\mathrm{E}_{t} s_{t+1}-s_{t}
$$

Finally, imposing market clearing in the world economy in which global consumption of home goods equals production in the home country and global consumption of final foreign goods equals production in the foreign country, it can be shown that

$$
\begin{gathered}
c_{t}=y_{t}-\alpha \eta \tau_{t} \\
c_{t}^{*}=y_{t}^{*}+(1-\alpha) \eta \tau_{t}
\end{gathered}
$$

Under the assumption of complete international risk-sharing in which $c_{t}=$ $c_{t}^{*}$, together with (11) and (12), the (log) term of trade fulfills

$$
\tau_{t}=\frac{1}{\eta}\left(y_{t}-y_{t}^{*}\right)
$$

Combining (13) with (11) and (12) gives

$$
c_{t}=c_{t}^{*}=(1-\alpha) y_{t}+\alpha y_{t}^{*}
$$




\subsection{Production}

The aggregate production function of home and foreign goods is given by

$$
\begin{aligned}
& y_{t}=n_{t}+\widetilde{a}_{t} \\
& y_{t}^{*}=n_{t}^{*}+\widetilde{a}_{t}^{*}
\end{aligned}
$$

where $\widetilde{a}_{t}$ and $\widetilde{a}_{t}^{*}$ denote the $(\log )$ exogenous productivity levels of the home and foreign countries.

The real marginal cost for firms in the home country is then given by

$$
\widetilde{\mathrm{mc}}_{t}=w_{t}-p_{t}-\widetilde{a}_{t}
$$

Using (1), (3), (15), (11) and (13),

$$
\mathrm{mc}_{t}=\left[\varphi+\frac{(1-\alpha)}{\sigma}+\frac{\alpha}{\eta}\right] y_{t}+\left[\frac{\alpha}{\sigma}-\frac{\alpha}{\eta}\right] y_{t}^{*}-(1+\varphi) a_{t}
$$

where $\mathrm{mc}_{t}$ is the log-deviation of the real marginal cost from the steady state value, which is $\log \frac{\epsilon-1}{\epsilon} . a_{t}$ is the log-deviation of the home productivity level from the steady-state level, which is normalized to $\frac{1}{1+\varphi} \log \frac{\epsilon}{\epsilon-1}$.

In the presence of nominal rigidity, firms set prices in a staggered fashion, as in Calvo (1983), which implies that inflation depends on the real marginal cost according to:

$$
\pi_{t}=\delta E_{t} \pi_{t+1}+\frac{(1-\theta)(1-\theta \delta)}{\theta} \mathrm{mc}_{t}
$$

In the absence of the nominal rigidity, on the other hand, firms adjust prices in each period to the nominal marginal cost plus the gross markup

$$
p_{t}=\log \frac{\epsilon}{\epsilon-1}+w_{t}-\widetilde{a}_{t}
$$

Define home potential output as the hypothetical level of output, in the flexible price equilibrium for a given level of foreign output. Using (20) and (18), potential output is then given by

$$
\bar{y}_{t}=b_{1} a_{t}-b_{2} y_{t}^{*}
$$

where

$$
\begin{gathered}
b_{1}=\frac{\widetilde{\sigma}(1+\varphi)}{1+\widetilde{\sigma} \varphi}>0 \\
b_{2}=\frac{\widetilde{\sigma}}{1+\widetilde{\sigma} \varphi} \alpha\left(\frac{1}{\sigma}-\frac{1}{\eta}\right)>0
\end{gathered}
$$

Productivity follows an $\mathrm{AR}(1)$ process 


$$
a_{t+1}=\rho_{a} a_{t}+\varepsilon_{t}^{a}
$$

where $\varepsilon_{t}^{a} \sim$ i.i.d. $N\left(0, \sigma_{\varepsilon}^{2}\right)$.

The output gap, $\widehat{y}_{t}$, is the deviation of $(\log )$ output $y_{t}$ from its potential level $\bar{y}_{t}$

$$
\widehat{y}_{t}=y_{t}-\bar{y}_{t}
$$

Foreign inflation, foreign real marginal cost and foreign potential output can be derived in the same manner.

Following Svensson (2004), in the case that the home country is interpreted as a small, open economy, the foreign country can be treated as exogenous. Without a loss of generality, all foreign variables are set to be constants. ${ }^{5}$

\subsection{Monetary policy objective}

I close the model by specifying how the central bank conducts its monetary policy. In particular, the central bank is mandated with the following intertemporal loss function

$$
L_{t}=\mathrm{E}_{t} \sum_{j=0}^{\infty}(1-\delta) \delta^{j} \frac{1}{2}\left[\left(\pi_{t+j}-\bar{\pi}\right)^{2}+\lambda \widehat{y}_{t+j}^{2}\right]
$$

where $\delta(0<\delta<1)$ denotes the constant subjective discount factor; $\bar{\pi} \geq 0$ denotes the inflation target and $\lambda \geq 0$ the relative weight on output gap variability.

\section{Optimal monetary policy under commitment}

\subsection{A straightforward way to derive the optimal path of the nominal exchange rate}

To derive the optimal path of the nominal exchange rate that is consistent with the commitment equilibrium, minimize (24) subject to the model equations that describe the behaviors of all variables. These model equations are (2), (4), (9), (11), (13), (18), (19), (21), (22) and (23).

For the ease of presentation, write the above model equations in the following state-space form

\footnotetext{
${ }^{5}$ Foreign variables can be assumed to follow some exogenous processes, such as AR(1). However, this will not add further insights and will not change the main conclusions of the paper. Assuming the foreign variables to follow AR(1), however, will add additional state variables into the system. As will be discussed further in the next section, given that the analysis in this paper is based on functional approximations, a system with too many state variables can yield excessively large approximation errors.
} 


$$
\left[\begin{array}{c}
X_{t+1} \\
H \mathrm{E}_{t} x_{t+1}
\end{array}\right]=A\left[\begin{array}{c}
X_{t} \\
x_{t}
\end{array}\right]+B i_{t}+\left[\begin{array}{c}
C \\
0
\end{array}\right] \varepsilon_{t+1}
$$

where $X_{t}$ is a vector of predetermined variables, $x_{t}$ is a vector of non-predetermined variables, $i_{t}$ is the nominal interest rate, and $\varepsilon_{t}$ is an $n_{\varepsilon}$-vector of exogenous zero-mean iid shocks. In this particular case

$$
\begin{aligned}
X_{t} & =\left(s_{t-1}, a_{t}, \tau_{t-1}\right) \\
x_{t} & =\left(\widehat{y}_{t}, \pi_{t}, \mathrm{mc}_{t}, y_{t}, \pi_{t}^{c}, \bar{y}_{t}, \tau_{t}, s_{t}, c_{t}\right)
\end{aligned}
$$

$A, B, C$, and $H$ are the corresponding matrices of the model parameters. $A$ and $B$ can be partitioned conformably with $X_{t}$ and $x_{t}$,

$$
A \equiv\left[\begin{array}{ll}
A_{11} & A_{12} \\
A_{21} & A_{22}
\end{array}\right], \quad B \equiv\left[\begin{array}{c}
B_{1} \\
B_{2}
\end{array}\right]
$$

Under the assumption that the central bank has access to a commitment device, the central bank can adopt optimal policy under commitment. ${ }^{6}$ In this case, the policy problem is

$$
\min _{\left\{X_{t}, x_{t}, i_{t},\right\}_{t \geq 0}} \mathrm{E}_{0} \sum_{t=0}^{\infty}(1-\delta) \delta^{t} L_{t}
$$

subject to (25), the initial condition

$$
X_{0}=\bar{X}_{0} \text { for a given } \bar{X}_{0}
$$

and a zero lower bound

$$
i_{t} \geq 0
$$

This otherwise standard monetary policy problem is augmented by the zero lower bound (29) which causes the model equations to be nonlinear. Thus, this problem is no longer linear quadratic and certainty equivalence ceases to hold. It can be shown that the first-order conditions of problem (27), together with the model equations (25), yield no closed-form solutions.

Nonetheless, problem $(27)$ can be solved numerically using the collocation method. ${ }^{7}$ To apply the collocation method, define the dual period loss as

$$
\widetilde{L}_{t} \equiv L_{t}+\gamma_{t}^{\prime}\left(-A_{21} X_{t}-A_{22} x_{t}-B_{2} x_{t}\right)+\frac{1}{\delta} \Xi_{t-1}^{\prime} H x_{t}
$$

where $\Xi_{t-1}$ is a new predetermined variable in period $t$ and $\gamma_{t}$ is introduced as a new control. $\Xi_{t-1}$ and $\gamma_{t}$ are related by the dynamic equation,

\footnotetext{
${ }^{6}$ See Svensson (2006) for a detailed description on optimal policy under commitment.

${ }^{7}$ Adam and Billi (2006) use the collocation method to solve a closed-economy model with a zero lower bound on the nominal interest rate. See Miranda and Fackler (2002) and Judd (1998) for a detailed description on the collocation method.
} 


$$
\Xi_{t}=\gamma_{t}
$$

Problem (27) can then be redefined as the recursive saddlepoint problem

$$
\max _{\left\{\gamma_{t}\right\}_{t \geq 0}} \min _{\left\{x_{t}, i_{t}\right\}_{t \geq 0}} \mathrm{E}_{0} \sum_{t=0}^{\infty}(1-\delta) \delta^{t} \widetilde{L}_{t}
$$

subject to $(31),(29),(28), \Xi_{-1}=0$, and

$$
X_{t+1}=A_{11} X_{t}+A_{12} x_{t}+B_{1} i_{t}+C \varepsilon_{t+1}
$$

The value function for the recursive dual saddlepoint problem, starting in any period $t$, satisfies the Bellman equation:

$\widetilde{V}\left(X_{t}, \Xi_{t-1}\right) \equiv \max _{\gamma_{t}} \min _{\left(x_{t}, i_{t}\right)}\left\{(1-\delta) \widetilde{L}\left(X_{t}, \Xi_{t-1} ; x_{t}, i_{t}, \gamma_{t}\right)+\delta \mathrm{E}_{t} \widetilde{V}\left(X_{t+1}, \Xi_{t}\right)\right\}$

Hence under this setup, $\left\{X_{t}, \Xi_{t-1}\right\}$ are state variables and $\left\{x_{t}, i_{t}, \gamma_{t}\right\}$ are controls.

\subsection{The collocation method and the curse of dimension- ality}

The problem with solving (33) using the collocation method is that the system is too large and we quickly run into the so-called curse of dimensionality. It should be noted that since the problem (33) is no longer linear quadratic due to the zero lower bound (29), the form of the value function $\widetilde{V}\left(X_{t}, \Xi_{t-1}\right)$ is unknown. The collocation method solves the problem numerically by approximating the value function $\widetilde{V}\left(X_{t}, \Xi_{t-1}\right)$ with a known linear function. In its approximation process, the collocation method discretizes the state space into a set of nodes. In this setup, we have 12 state variables. If we discretize the support of each variable such that it can take on 5 values, or 5 nodes, ${ }^{8}$ the total number of nodes in the discretized 12-dimensional state space will be $5^{12}$. This is simply too large for a personal computer to process. ${ }^{9}$

\footnotetext{
${ }^{8}$ This is the minimum number of nodes in which the approximation will yield a reasonably accurate solution.

${ }^{9}$ A related problem for a large system like (26) is that a few algorithms of the collocation method require inverting some matrices. It is possible that some equations in such a large system may introduce singularity into those matrices.
} 


\subsection{Solving a reduced-form model to avoid the curse of dimensionality}

To avoid the curse of dimensionality, we need to reduce the system into a manageable size. Given that we have only two target variables in the loss function, namely inflation and the output gap, we can reduce the system, to be solved by the collocation method, into a system of these two variables. Then, the optimal path of the nominal exchange rate can be computed from the solution derived from the collocation method.

In particular, using (21) and (18), one can show that the real marginal cost is proportional to the output gap

$$
\mathrm{mc}_{t}=\left(\varphi+\frac{1}{\widetilde{\sigma}}\right) \widehat{y}_{t}
$$

where

$$
\widetilde{\sigma}=\frac{\sigma}{1-\alpha+\alpha \frac{\sigma}{\eta}}
$$

Use (34) in (19), we then derive a standard Phillip curve

$$
\pi_{t}=\delta E_{t} \pi_{t+1}+\kappa \widehat{y}_{t}
$$

where $\kappa=\left(\varphi+\frac{1}{\widetilde{\sigma}}\right) \frac{(1-\theta)(1-\theta \delta)}{\theta}$.

Furthermore, from (14) and (4), it follows that we can write the Euler equation (2) as

$(1-\alpha) y_{t}+\alpha y_{t}^{*}=(1-\alpha) y_{t+1 \mid 1}+\alpha y_{t+1 \mid 1}^{*}-\sigma\left(i_{t}-\pi_{t+1 \mid t}-\alpha\left(\tau_{t+1 \mid 1}-\tau_{t}\right)-\rho\right)$

Using (13) gives

$$
y_{t}=y_{t+1 \mid 1}-\widetilde{\sigma}\left(i_{t}-\pi_{t+1 \mid t}-\rho\right)+\widetilde{\sigma}\left(\frac{\alpha}{\sigma}-\frac{\alpha}{\eta}\right)\left(y_{t+1 \mid 1}^{*}-y_{t}^{*}\right)
$$

Under the flexprice equilibrium, we can write (37) as

$$
\bar{y}_{t}=\bar{y}_{t+1 \mid 1}-\widetilde{\sigma}\left(\bar{r}_{t}-\rho\right)+\widetilde{\sigma}\left(\frac{\alpha}{\sigma}-\frac{\alpha}{\eta}\right)\left(y_{t+1 \mid 1}^{*}-y_{t}^{*}\right)
$$

where $\bar{r}_{t}$ is the natural interest rate, which is the real interest rate when prices are flexible, for a given level of foreign output. Given that productivity follows the $\operatorname{AR}(1)$ process (22), the natural interest rate fulfills

$$
\bar{r}_{t}=\left(1-\rho_{a}\right) \rho+p_{a} \bar{r}_{t-1}+\varepsilon_{r t}
$$


Subtract (38) and (37), we obtain a standard aggregate demand relation: ${ }^{10}$

$$
\widehat{y}_{t}=\widehat{y}_{t+1 \mid 1}-\widetilde{\sigma}\left(i_{t}-\pi_{t+1 \mid t}-\bar{r}_{t}\right)
$$

Hence, we can use (35), (39) and (40) to form a reduced form of model equations (25). Under this setup

$$
\begin{aligned}
X_{t} & =\left\{\bar{r}_{t}\right\} \\
x_{t} & =\left\{\widehat{y}_{t}, \pi_{t}\right\}
\end{aligned}
$$

and thereby we have three state variables, $\bar{r}_{t}, \Xi_{1 t-1}, \Xi_{2 t-1}$ where $\Xi_{1 t-1}$ and $\Xi_{2 t-1}$ are the Lagrange multipliers of (35) and (40). We then discretize the 3dimensional state space $S$ into a set of N collocation nodes $\mathrm{D}=\left\{s_{n} \mid n=1, \ldots, N\right\}$ where $s_{n} \in S$. The collocation method gives the optimal equilibrium of $\widehat{y}_{t}, \pi_{t}$, $i_{t}$ for each node in the state space

$$
\left\{\widehat{y_{t}}\left(s_{n}\right), \pi_{t}\left(s_{n}\right), i_{t}\left(s_{n}\right)\right\} \text { for each } s_{n} \in S
$$

The optimal equilibrium value of the nominal exchange rate for each node can be computed as

$$
\begin{aligned}
s_{t}\left(s_{n}\right) & =\tau_{t}\left(s_{n}\right)+p_{t}\left(s_{n}\right)-p_{t}^{*} \\
& =\tau_{t}\left(s_{n}\right)+\pi_{t}\left(s_{n}\right)+p_{t-1}-p_{t}^{*} \\
& =\frac{y_{t}\left(s_{n}\right)}{\eta}-\frac{y_{t}^{*}}{\eta}+\pi_{t}\left(s_{n}\right)+p_{t-1}-p_{t}^{*} \\
& =\frac{\widehat{y}_{t}\left(s_{n}\right)}{\eta}+\frac{\bar{y}_{t}\left(s_{n}\right)}{\eta}-\frac{y_{t}^{*}}{\eta}+\pi_{t}\left(s_{n}\right)+p_{t-1}-p_{t}^{*}
\end{aligned}
$$

\subsection{Discretionary policy}

As a basis for comparison, I solve the model under discretion. In contrast to optimal policy under commitment, the central bank has no access to a commitment technology and thus treats all future variables as given. More precisely, the central bank under discretion solves the problem in (27) on a period-by-period basis and taking into account the fact that the central bank cannot affect future variables. Such a problem has been solved in Adam and Billi (2007) on a closed-economy model. I apply their algorithm to the small, open economy model, as described earlier, to derive the equilibrium values of $\widehat{y}_{t}, \pi_{t}, i$ under discretion. The equilibrium exchange rate then is derived from (43).

\footnotetext{
${ }^{10}$ Thus, the natural interest rate can be interpreted as a demand shock. In the base-case analysis, the foreign output is set to be constant in order to facilitate the application of the collocation method. Therefore, negative natural interest rates, or contractionary disturbances, result primarily from negative productivity growth. In general, however, the natural interest rate also depends on the growth of foreign output. Thus, negative natural interest rates may result from any external factors that are related to recessions overseas.
} 


\section{Optimal inflation targets in the presence of the zero lower bound}

For the analysis in this paper, I calibrate the model parameters, rather than estimating. The reason is that the data from the recent episodes of low interest rate environments are not long enough to allow us to produce a statistically reliable estimation. By relying on estimated parameters, it will be difficult to simulate a low interest rate scenario that resembles and that can be used to analyze the recent real-world experiences that we are interested in.

I calibrate the model parameters such that the model can generate a low interest rate environment, and occasionally contractionary disturbances can send the economy into a liquidity trap. ${ }^{11}$ In particular, set $\sigma$ to 0.41 and $\eta$ to 0.99 as in Laxton et al. (1998). Note that, as explained in Svensson (2004), when $\sigma<\eta$, the "consumption channel" dominates over the effect of the home termsof-trade improvement from the increase in foreign output, which implies that home potential output is decreasing in foreign output, or $b_{2}>0$.

The elasticity of the marginal disutility of labor with respect to labor supply, $\varphi$, is assumed to be 3 , which implies a labor supply elasticity of $\frac{1}{3}$. The elasticity of substitution between intermediate goods $\epsilon$ is 6 , which implies a value of the steady-state markup of 1.2. The Calvo parameter $\theta$ is set equal to 0.75. The constant subjective discount factor $\delta$ is set to 0.99. Following Gali and Monacelli (2004), I assume the productivity level to follow an $\mathrm{AR}(1)$ process, with the coefficient of 0.9 .

Following Ball (1999) and Rudebusch and Svensson (1999), $\lambda$, the relative weight on the output gap, is set to unity. Nonetheless, the main findings in this paper are robust to different values of $\lambda$, as shown in an extended working-paper version of this paper.

It remains to be seen which target rate of inflation that we should use. Under the base-case calibration of the model parameters, I use (41) and (43) to run stochastic simulations of the commitment equilibrium and I vary $\bar{\pi}$, the target rate of inflation, by 25 basis points from 0 to 3 percent. Table 1 presents macroeconomic outcomes under different inflation targets. As evident from the table, the inflation target of 2 percent leads to the lowest loss, or the best stabilization performance. Thus, I will use the inflation target of 2 percent as the base case.

It should be noted that if there were no lower bound, the optimal target of inflation would be zero. To see this, set $\bar{\pi}$ to zero. It can be solved from (35) and (40) that in the optimal equilibrium, $\pi_{t}=\bar{\pi}=0, x_{t}=0$ and $i_{t}=\bar{r}_{t}$ and the central bank can stabilize both inflation and the output gap simultaneously and instantly. To confirm this conjecture, using the collocation method, I run stochastic simulations as above but on a hypothetical model economy without the zero lower bound on the nominal interest rate. Table 2 reports the con-

\footnotetext{
${ }^{11} \mathrm{~A}$ liquidity trap is defined as a situation in which the nominal interest rate is constrained at the zero lower bound.
} 
Table 1: Macroeconomic outcomes under different target rates of inflation

\begin{tabular}{ccc}
\hline Inflation target $(\%)$ & Conditional loss & Frequency of bind $(\%)$ \\
\hline 0.00 & 21.35 & 100.00 \\
0.25 & 14.00 & 99.88 \\
0.50 & 8.54 & 97.97 \\
0.75 & 4.78 & 89.11 \\
1.00 & 2.33 & 75.34 \\
1.25 & 0.95 & 44.74 \\
1.50 & 0.35 & 24.97 \\
1.75 & 0.16 & 6.77 \\
2.00 & 0.13 & 2.09 \\
2.25 & 0.14 & 0.22 \\
2.50 & 0.18 & 0.01 \\
2.75 & 0.21 & 0.00 \\
3.00 & 0.25 & 0.00 \\
\hline
\end{tabular}

Note: These results are derived from stochastic simulations over 1,000 periods for 2,000 trials. Conditional losses are the average values of the intertemporal loss (24) over the 1000 periods. The frequency of bind is the percentage of the total number of periods in which the nominal interest rate is zero.

ditional losses for each target rate of inflation under the hypothetical model economy. It is clear from the table that in the absence of the zero lower bound, the optimal target rate of inflation is zero. Furthermore, at the inflation target of zero, the central bank can stabilize the economy completely with the loss of zero, as predicted.

In reality, the zero lower bound exists and thus targeting inflation at a very low rate will be suboptimal. This is because the zero lower bound imposes a constraint on the ability of the central bank to stabilize the economy. The third column of table 1 reports the percentage of the total number of periods in which the nominal interest rate is zero. It is evident that the lower the target rate of inflation, the more often the nominal interest rate hits the zero lower bound. This is because at lower inflation targets, nominal interest rates on average are lower, generally close to the zero lower bound. This can also be seen from figure 1 which compares the simulated paths of the nominal interest rate under the inflation targets of 1 percent and 3 percent.

Occasionally the central bank is required to create negative real interest rates to offset contractionary disturbances. This however is difficult to achieve in a low interest rate environment since the nominal interest rate cannot go below zero. Therefore, at a very low inflation target, the central bank may not be able to stabilize the economy at will.

At a very high inflation target, on the other hand, the central bank will not be able to effectively stabilize the economy either. It should be clear from figure 1 that at a very high inflation target, such as 3 percent, the zero lower bound is no longer a constraint for monetary policy. However, the higher the target rate of inflation, the more difficult for the central bank to stabilize the output gap. To see this, iterate (35) forward 
Table 2: Macroeconomic outcomes in the absence of the zero lower bound

\begin{tabular}{cc}
\hline Inflation target $(\%)$ & Conditional loss \\
\hline 0.00 & 0.0000 \\
0.25 & 0.0018 \\
0.50 & 0.0070 \\
0.75 & 0.0158 \\
1.00 & 0.0281 \\
1.25 & 0.0439 \\
1.50 & 0.0632 \\
1.75 & 0.0860 \\
2.00 & 0.1124 \\
2.25 & 0.1422 \\
2.50 & 0.1756 \\
2.75 & 0.2124 \\
3.00 & 0.2528 \\
\hline
\end{tabular}

Note: These results are derived from stochastic simulations over 1,000 periods for 2,000 trials in a hypothetical model economy that excludes the zero lower bound on the nominal interest rate. Conditional losses are the average values of the intertemporal loss (24) over the 1000 periods.

$$
\pi_{t}=E_{t} \sum_{i=0}^{\infty} \delta^{i}\left(\kappa x_{t+i}\right)
$$

Thus, if the central bank attempts to achieve an inflation rate other than zero, it will not be able to close the output gap. This is a classic trade-off between achieving zero average inflation and macroeconomic stabilization in the presence of the lower bound, as pointed out by Summers (1991). Under the base-case calibration of the model parameters, it turns out that the inflation target of 2 percent is the optimal target that best balances the adverse effect from the zero lower bound with the inability of the central bank to simultaneously achieve zero average inflation and close the output gap.

\section{Optimal exchange rate policy in a low interest rate environment}

The left panel of figure 2 compares the policy functions of the nominal exchange rate under the discretionary equilibrium and under the commitment equilibrium. ${ }^{12}$ Under the discretionary equilibrium, the central bank does not

\footnotetext{
${ }^{12}$ These are the equilibrium levels of the nominal exchange rate as a function of the natural interest rate. The presence of the zero lower bound prohibits us from deriving a closed-form solution of the policy function. Nonetheless, the collocation method yields solutions in the form of the equilibrium value of the nominal exchange rate for each collocation node in the discretized state space. Setting the two Lagrange multipliers to zero, we can then plot the nominal exchange rate as a function of the natural interest rate. In the figure, I use a refined grid, with 90 nodes between the natural interest rates of -4.5 to 4.5 percent. Notice that with the presence of the zero lower bound, the policy function of the nominal exchange rate (and
} 
Figure 1: Simulated nominal interest rates

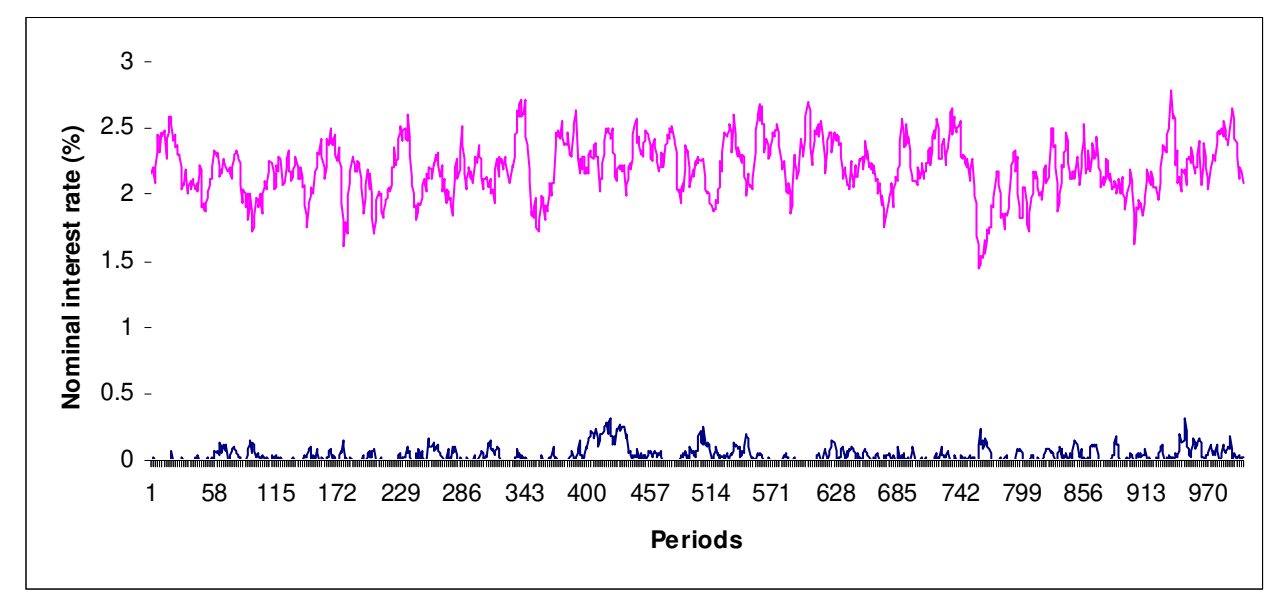

Note: The figure is derived from stochastic simulations over 1000 periods. The lower path is simulated under the target rate of 1 percent. The upper path is under 3 percent.

seek to influence private agents' expectations, most likely because its credibility is in doubt. Therefore, the central bank makes decisions on monetary-policy making period-by-period. Under the commitment equilibrium, on the other hand, the central bank can make a credible promise on its future action and thus influence private agents' expectations. The inflation target and thus the average inflation rate is set to 2 percent.

The solid line portrays the nominal exchange rate under the commitment equilibrium. The dashed line is that under the discretionary equilibrium. As evident from the figure, in response to a large positive demand shock such that the natural interest rate is 1.2 percent or higher, the nominal exchange rate appreciates regardless of whether the central bank can commit. However, when the economy is hit by a negative demand shock such that the natural interest rate is -3.5 percent or lower, the fact that whether or not the central bank can commit yields different implications in terms of the nominal exchange rate. That is, if the central bank follows discretionary policy, the nominal exchange rate appreciates. On the other hand, under commitment policy, the nominal exchange rate depreciates.

The reason that optimal policy under commitment and under discretion leads to the different outcomes is because in response to a negative demand shock, the central bank needs to cut nominal interest rates. Nonetheless, the extent to which the central bank can ease is limited by the presence of the zero lower bound on the nominal interest rate. This is evident from the right panel of figure 2 , which presents the equilibrium levels of the nominal interest rate as

the nominal interest rate) is nonlinear. As shown in Figure 3, when the zero lower bound is excluded, the policy function is linear, as usually derived in a linear quadratic setup. 
Figure 2: The nominal exchange rate and the nominal interest rate in the commitment and the discretionary equilibrium
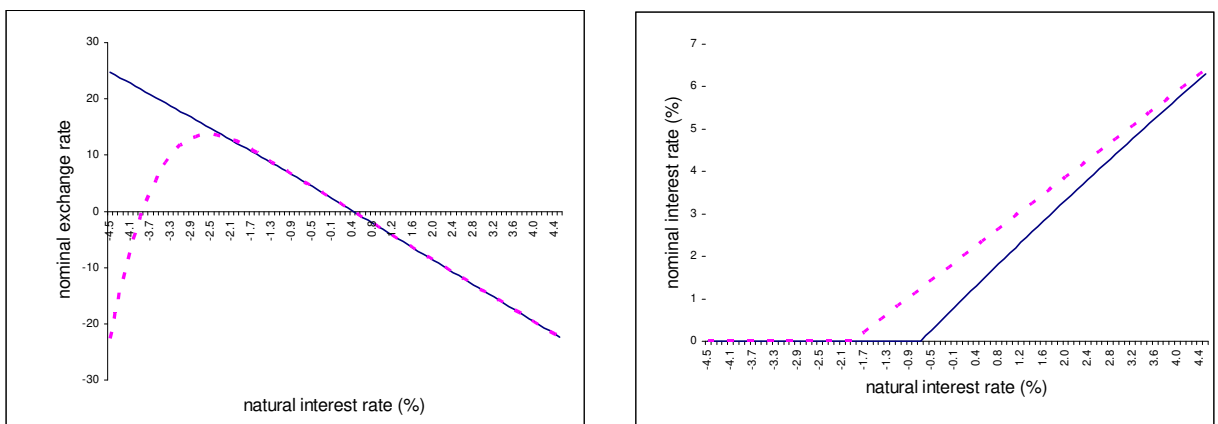

Note: these are the policy functions of the nominal exchange rate and the nominal interest rate. The two Lagrange multipliers are set to zero. The solid lines are those under the commitment equilibrium. The dashed lines are those under the discretionary equilibrium.

a function of the natural interest rate. In the figure, the nominal interest rate is constrained at the zero lower bound when the natural interest rate becomes significantly negative.

To confirm the conjecture that the zero lower bound on the nominal interest rate is a source of the difference between the movements in exchange rates under the commitment equilibrium and those under the discretionary equilibrium, I conduct the analysis on a hypothetical model economy that excludes the zero lower bound. Figure 3 presents the equilibrium levels of the nominal exchange rate and the nominal interest rate under this hypothetical scenario.

Without the constraint imposed by the zero lower bound, the equilibrium level of the nominal exchange rate under commitment and that under discretion become qualitatively similar. Particularly, in response to a large negative demand shock, both commitment policy and discretionary policy prescribe a nominal depreciation of the exchange rate. Thus, it is the zero lower bound that is the source of the difference in the exchange-rate movements between the two policy regimes.

To understand the intuition behind this result, it should be noted that under floating exchange rates, as it is the case in the model economy in this paper, the central bank cannot control exchange rates directly. The central bank however may influence exchange rates via adjusting the nominal interest rate. Under perfect capital mobility, the nominal exchange rate is related to the nominal interest rate according to the uncovered interest parity:

$$
s_{t}=-i_{t}+i_{t}^{*}+\mathrm{E}_{t} s_{t+1}
$$

(44) implies that under discretionary policy in which the central bank takes private agents' expectations as given, the only way that the central bank can 
Figure 3: The nominal interest rate and the nominal exchange rate in the absence of the zero lower bound
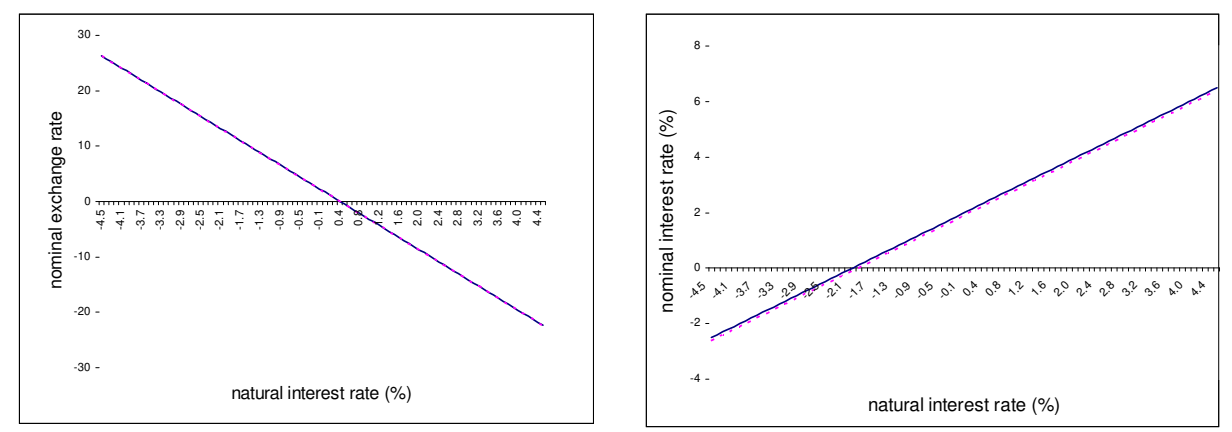

Note: These are the policy functions of the nominal exchange rate and the nominal interest rate in the absence of the zero lower bound. The two Lagrange multipliers are set to zero. The solid lines are those under the commitment equilibrium. The dashed lines are those under the discretionary equilibrium.

create a nominal depreciation is to lower the nominal interest rate. In response to a decline in the natural interest rate, which is interpretable as a contractionary disturbance, the central bank is required to cut the nominal interest rate. The extent to which the nominal interest rate is to be lowered has to match the decline in the natural interest rate. As evident from (40) and (35),

$$
\begin{gathered}
\widehat{y}_{t}=\widehat{y}_{t+1 \mid 1}-\tilde{\sigma}\left(i_{t}-\pi_{t+1 \mid t}-\bar{r}_{t}\right) \\
\pi_{t}=\delta E_{t} \pi_{t+1}+\kappa \widehat{y}_{t}
\end{gathered}
$$

this will allow the central bank to stabilize inflation as well as the output gap simultaneously and instantaneously. However, in the low interest rate environment, the scope that the nominal interest rate can be lowered will be limited by the zero lower bound. In response to a large decline in the natural interest rate, the central bank will not be able to cut the nominal interest rate by the required amount. This is evident from the right panel of figure 2 which shows that the nominal interest rate hits zero after the natural interest rate drops below -2 percent. If the zero lower bound did not exist, the central bank would be required to lower the nominal interest rate below zero, as highlighted in the right panel of figure 3 . This implies that, amid contractionary disturbances, the nominal interest rate in the home country will be too high, which will induce capital to flow into the home country and cause the nominal exchange rate to appreciate.

Under commitment policy, however, the central bank can affect the expected exchange rate, $\mathrm{E}_{t} s_{t+1}$ in (44). Thus, even though the central bank cannot lower interest rates sufficiently due to the constraint imposed by the zero lower bound, 
the central bank can still cause the exchange rate to depreciate by creating an expected depreciation of its currency. It follows from (44) that

$$
\mathrm{E}_{t} s_{t+1}=\mathrm{E}_{t} \sum_{i=0}^{\infty}\left(i_{t+1+i}^{*}-i_{t+1+i}\right)
$$

That is, the expected nominal exchange rate depends on the expected future path of the gap between the foreign and the domestic nominal interest rates. For a small open economy in which the foreign nominal interest rate is exogenous, the nominal exchange rate then primarily depends on the expected future path of the domestic nominal interest rate.

The right panel of figure 2 suggests that the nominal interest rate under the commitment equilibrium is lower than that under the discretionary equilibrium for every level of the natural interest rate. It is useful to interpret the right panel of figure 2 as a scenario in which the economy is hit by a large negative demand shock in period 0 . This is the point at the left end of the panel. As we move to the right of the panel, the natural interest rate continues to recover over time until it reaches 4.5 percent.

Under this interpretation, the panel portrays the paths of the nominal interest rate over time. In response to a large negative demand shock, commitment policy requires the central bank to leave the nominal interest rate at the lower bound longer than what would be prescribed under discretionary policy. Later when the natural interest rate starts to rebound, and the nominal interest rate is raised above the zero lower bound, the nominal interest rate under the commitment equilibrium is still below that under the discretionary equilibrium.

Thus, one way to create an expected depreciation is for the central bank to make a credible promise that monetary policy will remain loose going forward even after the natural interest rate rebounds to a positive level. If the central bank's promise is credible, private agents will expect the exchange rate to depreciate. This in turn allows the exchange rate, under the commitment equilibrium, to depreciate today even though the scope that interest rates can be lowered is limited by the zero lower bound.

The ability of the central bank to make a credible promise has a value. Table 3 compares macroeconomic outcomes under commitment with those under discretion. It is clear that commitment policy performs substantially better than discretionary policy. The conditional loss, which measures the inability of the central bank to stabilize inflation and the output gap over the simulation periods, is 0.1255 under commitment, compared to 0.6897 under discretion. This suggests that in a low interest rate environment, it is indeed optimal for the central bank to engineer a nominal depreciation in response to contractionary disturbances.

\section{The magic of foreign trade}

As shown in the previous section, in the presence of the zero lower bound, the central bank may not be able to adjust the nominal interest rate as aggres- 
Table 3: The stabilization performance of commitment and discretionary policy

\begin{tabular}{lcc}
\hline & Commitment & Discretion \\
\hline \multicolumn{1}{c}{ Loss } & 0.1255 & 0.6897 \\
\hline $\begin{array}{l}\text { Note: These results are derived from stochastic simulations over 1,000 periods for 2,000 trials under the target inflation } \\
\text { of } 2 \text { percent. }\end{array}$
\end{tabular}

sively as the central bank prefers otherwise. This is especially true in the low interest rate environment in which the nominal interest rate will occasionally be constrained at the zero lower bound. There is no such a constraint on the movements of exchange rates, however. As highlighted in the left panel of figure 2, the nominal interest rate is constrained at zero as soon as the natural interest rate starts dropping below -0.5 percent. The nominal exchange rate however can keep rising as the natural interest rate falls as far as to -4.5 percent. Hence, exchange rates may potentially be a more effective policy instrument in this environment. But this requires that exchange rates can independently affect the real economy. In other words, we need to examine the importance of the exchange rate channel on the transmission mechanism.

As pointed out by many authors, one possible mechanism in which exchange rates can have an independent effect on the economy is through foreign trade. ${ }^{13}$ A nominal depreciation can cause the country's exports to be more competitive in the world markets. A rise in exports in turn can stimulate aggregate demand. This implies that if exchange rates indeed play a role on the transmission mechanism, we should expect a nominal depreciation to have a larger effect on relatively open economies in which exports account for a large fraction of output.

In particular, commitment policy, as noted in the previous section, can improve the stabilization performance over discretionary policy. The only difference between the two policy regimes is that in response to contractionary disturbances, it is optimal to engineer a nominal depreciation under the commitment equilibrium while under the discretionary equilibrium the exchange rate appreciates. To examine whether it is this difference in exchange-rate movements that contributes to the superior performance of commitment policy, consider varying $\alpha$, which measures the economy's openness, around its basecase value of 0.4 from 0.1 to 0.9 . Figure 4 plots the differences in the losses between commitment policy and discretionary policy for each value of $\alpha$.

When $\alpha=0.9$, which corresponds to the case that the economy is most open, commitment policy can improve macroeconomic outcomes over discretionary policy by the most. In other words, the exchange rate policy of creating a nominal depreciation is at its best when exports account for the largest fraction of the total output. Intuitively, it follows from (11) that

$$
\begin{aligned}
& y_{t}=c_{t}+\alpha \eta \tau_{t} \\
& y_{t}=c_{t}+\alpha \eta\left(p_{t}^{*}+s_{t}-p_{t}\right)
\end{aligned}
$$

${ }^{13}$ See for example, McKinnon (1999), Meltzer (1999) and McCallum (2000). 
Figure 4: The difference in losses between discretionary policy and commitment policy for different degrees of openness

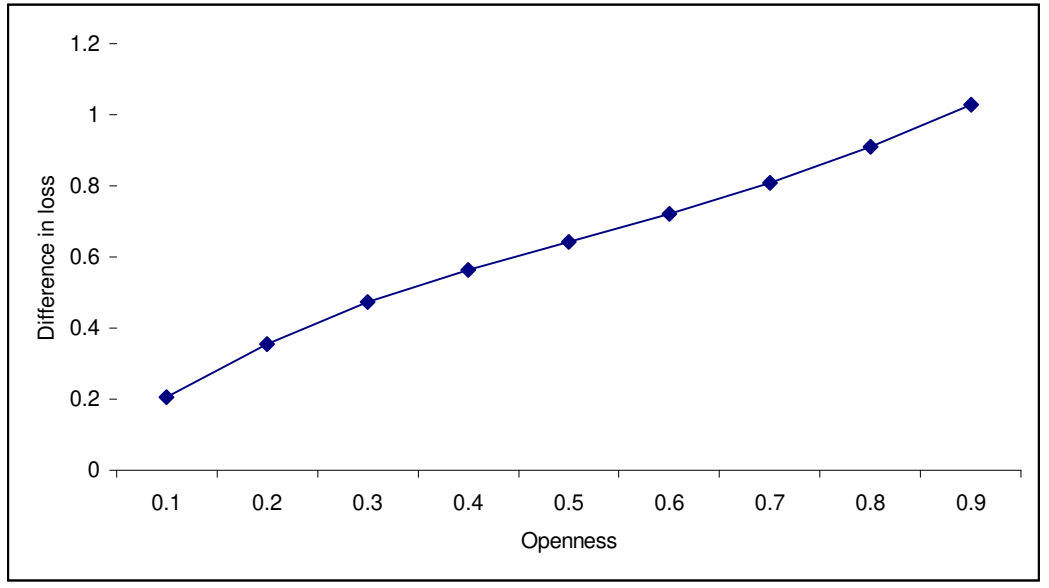

That is, in equilibrium, output equals aggregate demand and the second term on the right is interpreted as net exports. To respond to a contractionary disturbance, the central bank can usually lower interest rates to stimulate aggregate demand. In a low interest rate environment, the scope of monetary-policy easing however is limited by the zero lower bound. However, operating in a small open economy, the central bank can resort to exchange rates as another policy instrument. That is, given sticky prices, as in our model economy, a nominal depreciation will lead to a real depreciation. This in turn can stimulate aggregate demand through an expenditure switching effect. Given that inflation depends on demand according to (40), inflation can then be stabilized. Generating a nominal depreciation thus allows the central bank to stabilize the economy even though the nominal interest rate is no longer effective.

The higher the degree of openness $\alpha$, the more effective the exchange rate will be as a policy instrument. For an economy that is relatively open, exchange rate policy will become more important. This can also be seen from Table 4, which presents macroeconomic outcomes of an economy that is extremely open, as characterized by $\alpha=0.9$. In this case, the optimal target rate of inflation becomes 1 percent. This is lower than the optimal target of 2 percent in the base-case economy in which $\alpha=0.4$. That is, the more open the economy is, the lower average inflation the central bank can achieve. Given that the extremely open economy with $\alpha=0.9$ can achieve lower average inflation, it can also achieve a better macroeconomic outcome with a loss of 0.05 , compared to 0.13 under the base-case economy with $\alpha=0.4$. With a high degree of openness, the 
Table 4: Macroeconomic outcomes of an extremely open economy

\begin{tabular}{ccc}
\hline Inflation target $(\%)$ & Conditional loss & Frequency of bind $(\%)$ \\
\hline 0.00 & 10.33 & 95.40 \\
0.25 & 4.44 & 69.90 \\
0.50 & 1.31 & 37.81 \\
0.75 & 0.23 & 7.40 \\
1.00 & 0.05 & 0.23 \\
1.25 & 0.07 & 0 \\
1.50 & 0.12 & 0 \\
1.75 & 0.15 & 0 \\
2.00 & 0.17 & 0 \\
2.25 & 0.20 & 0 \\
2.50 & 0.24 & 0 \\
2.75 & 0.29 & 0 \\
3.00 & 0.35 & 0 \\
\hline Note: These results are derived from stochastic simulations over 1,000 periods for 2,000 trials under $\alpha=0.9$. \\
Conditional losses are the average values of the intertemporal loss (24) over the 1000 periods. The frequency of bind is \\
the percentage of the total number of periods in which the nominal interest rate is zero.
\end{tabular}

extremely open economy can stabilize both inflation and the output gap more effectively because the exchange rate policy to create a nominal depreciation becomes even more powerful in this case. Since net exports account for a large fraction of output, a given nominal depreciation leads to a larger rise in aggregate demand. This allows the central bank in such an economy to offset contractionary disturbances more effectively even though the nominal interest rate becomes totally powerless as a policy instrument. A policy lesson here is that trade liberalization, if increases the degree of openness, may lead to lower average inflation and thus better stabilization performance of monetary policy.

\section{The era of low interest rates in the Far East}

The most notorious episode of low interest rates has been the economic experience of Japan in which short-term nominal interest rates have been constrained at zero from 2001 to 2006, with strings of recessions and deflations since the second half of the 1990s. Such a phenomenon in which the nominal interest rate is constrained at zero and therefore the central bank may not be able to stimulate the economy via the interest rate channel, is known as a liquidity trap.

However, from the end of 2005, deflationary pressure seems to be subsiding and the Bank of Japan raised the uncollateralized overnight call rate for 25 basis points in July 2006 and for another 25 basis points in February 2007 to 0.5 percent. Nonetheless, such a low interest rate still poses a challenge for monetary policy, not on how to escape from deflation, but on how to prevent deflation. For one thing, with low interest rates, future contractionary shocks may easily send the economy back into a liquidity trap. This was precisely what happened in Japan in late 2000 when the uncollateralized overnight call 
rate had stood at 0.25 percent since October 2000 but deteriorating economic conditions and concern over deflation forced the Bank of Japan to lower the call rate to 0.15 percent and later to virtually zero after the Bank adopted quantitative monetary easing in March 2001. ${ }^{14}$ Thus, it is still important to study how central banks should conduct monetary policy in this low interest rate environment.

More importantly, the phenomenon of low interest rates is by no means unique to Japan. Figure 5 presents measures of short-term interest rates in four Asian economies, namely China, South Korea, Taiwan (China), and Thailand. Figure 5 shows that prior to the year 1999, the short-term interest rates in all four Asian economies were relatively high on average about 10 percent in China, South Korea and Thailand and about 7 percent in Taiwan (China). Thereafter, the short-term interest rates in all four economies dropped sharply. Their interest rates were at the lowest during 2002-2005, below two percent in Taiwan (China) and Thailand and around three percent in the case of China and South Korea. Although the short-term interest rates have risen in the past two years, in line with the US's federal funds rate, they are all remain low by the historical standard. Furthermore, the episode of extremely low interest rates, as observed during 2002-2005, may very well reemerge in the future should these economies are hit by contractionary disturbances. ${ }^{15}$

\subsection{Attempts to generate currency depreciation in the Far East}

Interestingly, it appears that since 2000, the central banks in these Asian economies have attempted to utilize exchange rate policy, with an aim to achieve the exchange rates that they desire. One common practice is official intervention in which central banks buy or sell foreign exchange to influence exchange rates. Taiwan (China) and South Korea stand out in this respect. Since 2000, it appears that Taiwan (China) and South Korea have aggressively purchased US

\footnotetext{
${ }^{14}$ Under quantitative monetary easing, the Bank of Japan's operating instrument was changed from the uncollateralized overnight call rate to the outstanding balance of current accounts held at the Bank, which together with notes and coins, constitute the monetary base. Subsequently, the Bank aggressively raised the target level of the current account balance. As a result, the monetary base rose for more than $60 \%$ between 2001-2004.

${ }^{15}$ It should be noted that the constraint on the ability of these Asian central banks to adjust short-term interest rates may be more severe than it seems. To be more precise, central banks, especially those in emerging markets, are discouraged from lowering short-term interest rates below certain levels due to some other considerations that are not captured in the New Keynesian transmission mechanism. In this case, the relevant lower bound on the nominal interest rate may be a small positive number above zero. For example, it appears that emerging-market central banks are usually refrained from cutting their interest rates to very low levels to avoid massive capital outflows. Another, more specific, example, in March 2007, Dr. Atchana Waiquamdee, Deputy Governor of the Bank of Thailand, explained that the Bank did not want to cut nominal interest rates further for fear that interest income earned by households from their saving deposits would drop sharply. Given that interest accounts for a significant fraction of disposable income in Thailand, cutting nominal interest rates to a very low level, even not zero, may lead to a sharp decline in consumption spending.
} 
Figure 5: Measures of short-term interest rates in four selected Asian economies
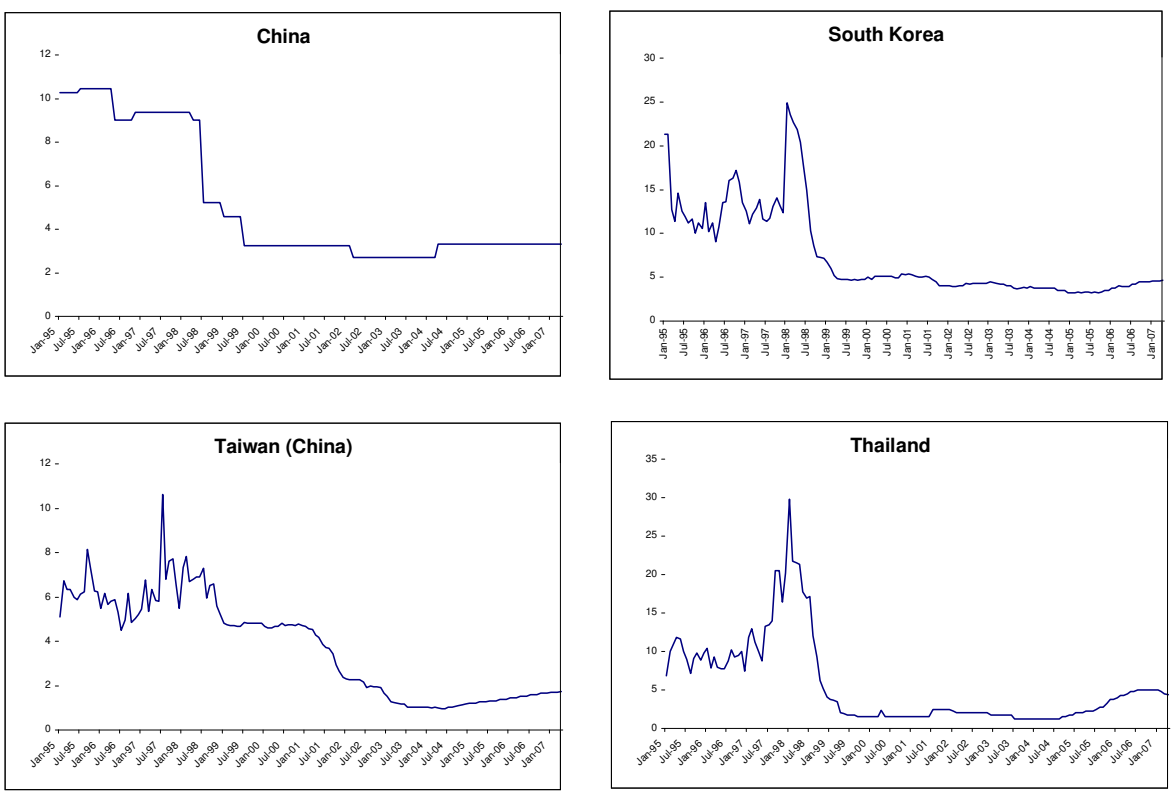

Source: Datastream. The measure of short-term interest rates in China is 20-day relending rate. Those of South Korea, Taiwan (China) and Thailand are overnight call rate, overnight interbank swap rate, and 14-day repo rate, respectively

dollars to counter upward pressure on their currencies. Table 5 compares international reserves accumulation in Taiwan (China) and South Korea with other emerging market economies. At the end of 2006, Taiwan (China) and South Korea had the largest international reserves as a percentage of GDP in the world, at 65 percent and 23 percent respectively (Mohanty and Turner, 2006).

Alternatively, central banks may also intervene indirectly in foreign-exchange markets. One way to do so is to impose capital controls, which are restrictions on international transactions in financial assets. A recent example, the Bank of Thailand introduced a capital control measure, requiring financial institutions to deposit 30 percent of foreign-currency inflows from non-residents in interest-free accounts with the Bank. According to this measure, overseas investors would have to leave such deposits in Thailand for one year, or face an early withdrawal penalty (Economist Intelligence Unit, 2007). The 30-percent deposit is in effect a withholding tax on capital inflows, an attempt to create a depreciation of the Thai currency.

Perhaps, the most effective way to achieve a desired exchange rate is to adopt a fixed exchange rate regime. This is precisely what China has done. Despite pressure from the US to allow the renminbi to float freely, China instead adopted a crawling peg after the country abolished the peg to the US dollar 
Table 5: International reserves accumulation in emerging markets

\begin{tabular}{|l|c|c|c|c|}
\hline & \multicolumn{3}{|c|}{ Change } & Stock \\
\cline { 2 - 4 } & $1990-93$ & $1995-96$ & $2000-5$ & July 2006 \\
\hline Asia & 119 & 110 & 1,178 & 2,025 \\
China & 4 & 53 & 664 & 941 \\
India & 7 & 0 & 99 & 156 \\
South Korea & 5 & 8 & 136 & 225 \\
Taiwan(China) & 10 & -4 & 147 & 260 \\
Latin America & 71 & 49 & 83 & 244 \\
Central Europe & 16 & 21 & 39 & 99 \\
Russia & 10 & 7 & 167 & 243 \\
Middle East & -3 & 8 & 50 & 89 \\
Total & 214 & 195 & 1,571 & 2,710 \\
\hline
\end{tabular}

Source: Mohanty and Turner (2006)

in July 2005. Under the crawling peg, the renminbi has been permitted to adjust not more than 0.13 percent a year. As a result, from July 2005 to the end of 2006, the renminbi appreciated only 5.6 percent against the US dollar (US Treasury Department, 2006). Adopting the crawling peg, as opposed to allowing the renminbi to float freely, essentially is an attempt for China to prevent the renminbi from appreciating and thus to keep its currency at an artificially low level.

It should be noted that the inclination of these East Asian economies to actively manage their currencies may be attributable to the legacy of these countries's export-led growth policy during the East Asian Miracle era. In particular, all the countries mentioned above relied heavily on their export sectors in achieving the extraordinary economic growth, that began in the 1960s for the two "tiger" economies of Taiwan (China) and South Korea, and later in the 1980s for China and Thailand. Even until now, exports as a share of GDP for these countries remain remarkably high, as highlighted in Table 6. Given the importance of their export sectors, these countries have a tendency to 'manipulate' their exchange rates, to make sure that their export sectors remain competitive in the world markets.

The question is whether it is desirable for the central banks in these countries to pursue such policy. The analysis in this paper suggests that it is desirable, especially in the low interest rate environment, to attempt to create a nominal depreciation to offset contractionary disturbances. That is, given the limited scope that nominal interest rates can be eased, the central banks should resort to exchange rates as a policy tool to stimulate aggregate demand. This is especially true for these Asian economies, which are relatively open, and thereby, the exchange rate channel can play a large role on these countries' transmission mechanism.

The analysis in this paper is also applicable to the case of Japan. As already noted, despite having escaped from the liquidity trap in which the nominal 
Table 6: Exports as a percentage of GDP, 2005

\begin{tabular}{lc}
\hline & Exports (\% of GDP) \\
\hline China & 37 \\
South Korea & 42 \\
Taiwan (China) & 57 \\
Thailand & 74 \\
Brazil & 17 \\
India & 21 \\
Mexico & 30 \\
Germany & 40 \\
United States & 10
\end{tabular}

interest rate was constrained at zero, Japan still has a very low interest rate. In this low interest rate environment, the analysis in this paper suggests that Japan should rely on exchange rate policy in managing aggregate demand. In particular, it will be optimal for the country to create a nominal depreciation in yen to counteract contractionary disturbances.

\subsection{Implementing nominal depreciation by commitment- based policy}

Figure 6 shows the nominal exchange rates, from Jan 2002 to Jan 2007, of the selected Asian economies that adopt floating exchange rates. The exchange rate of yen per US dollar is also included for comparison. The nominal exchange rates at the beginning of 2002 are normalized to 100.

During the period of 2002-2006, when the nominal interest rates in South Korea, Taiwan (China) and Thailand were unusually low, these countries aggressively intervened in foreign exchange markets to force their currencies to depreciate. It should be noted however that, under floating exchange rates, these countries cannot control their exchange rates directly. Thus, the monetary authorities in these countries might not necessarily succeed in forcing their exchange rates to depreciate.

Figure 6 confirms this conjecture. It is evident that the nominal exchange rates have appreciated somewhat despite the fact that these Asian countries have attempted a number of measures to keep their currencies weak.

Movements in exchange rates certainly can be affected by several factors, most of which are not captured in the model in this paper. ${ }^{16}$ The analysis in this paper nonetheless offers a plausible explanation. As noted earlier, in a

\footnotetext{
${ }^{16}$ In the context of these Asian economies, the upward pressure on their currencies may result from the expectations of an inevitable decline in the US dollar due to the US current account deficit. Another contributing factor is massive capital inflows due to yen carry trades. These are trading strategies in which investors borrow in yen, a low-yield currency, to invest in higher-yield currencies.
} 
Figure 6: The nominal exchange rates of the selected Asian economies, 20022007

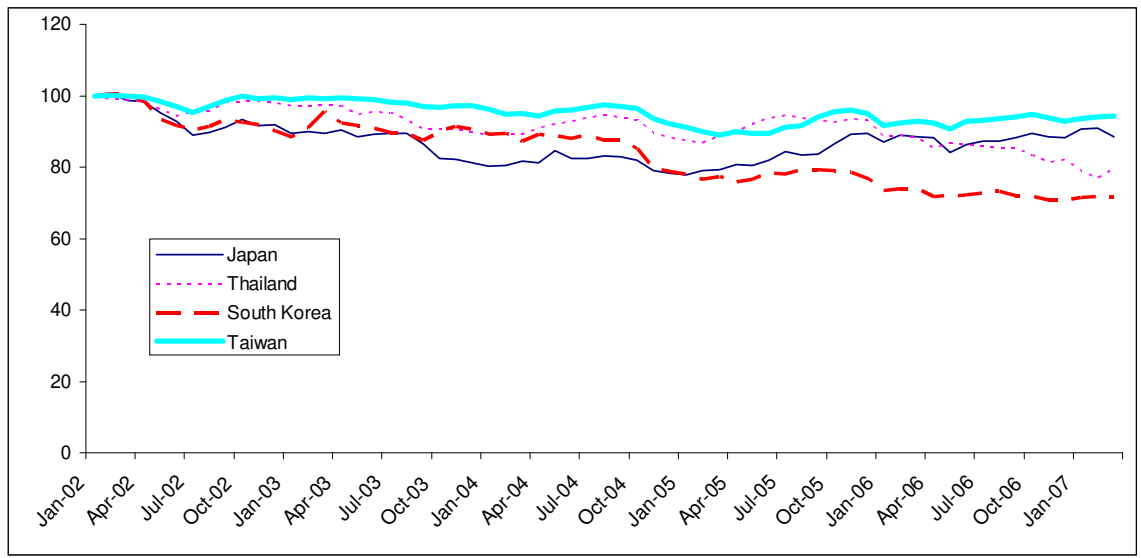

Source: Datastream. The nominal exchange rates are quoted in terms of the currency of interest per US dollar. The rates in Jan 2002 are normalized to 100.

low interest rate environment, it is difficult for the central bank to engineer a nominal depreciation in response to contractionary disturbances, especially in the case that the central bank follows discretionary policy. The reason is, in this environment, the scope that the nominal interest rate can be cut is limited. As such, if the economy is hit by a contractionary shock, the central bank will not be able to engineer a drop in the real interest rate and thus will not be able to rely on the conventional interest rate channel. The relatively high real interest rate will induce capital to flow in. Knowing this, financial markets will expect the currency to appreciate and this makes it difficult for the central bank to engineer a nominal depreciation.

The analysis in this paper suggests that in order for the Asian central banks to successfully create a nominal depreciation, they need to follow commitment policy. That is, the central banks have to make a credible promise, that the central banks will attempt to keep their currencies weak going forward even after there will be no more contractionary disturbances. If the central banks' promise is perceived by financial markets to be credible, the currencies will be expected to remain weak. This will allow the central banks to create a nominal depreciation even though there is little room for interest rates to be cut. 


\section{Conclusions}

This paper studies optimal exchange rate policy in a low interest rate environment, a phenomenon that has become prevalent, especially in several Asian economies and Japan after July 2006. The paper finds that in such an environment, it is optimal for the central bank of a small open economy to engineer a nominal depreciation of its currency to offset contractionary disturbances. The intuition is that in the low interest rate environment, the scope of monetary policy easing is limited by the zero lower bound, which causes the nominal interest rate to be ineffective as a policy tool. In this situation, the central bank should resort to exchange rate policy. Given that prices are sticky, as in our model, a nominal depreciation will cause exports to be more competitive in the world markets. This in turn will boost aggregate demand and allow the central bank to prevent the economy from falling into a deflationary spiral.

However, as the recent experience of several Asian economies suggests, unless the central bank adopts a fixed exchange rate regime like China, it is not always possible to achieve a nominal depreciation. Orphanides and Wieland (2000) and Coenen and Wieland (2003), who also recommend that in the presence of the zero lower bound, the central bank should rely on the exchange-rate channel, suggest that the central bank can create a depreciation via a portfolio-balance effect. In particular, this can be done by expanding the monetary base on a large scale. This paper, on the other hand, argues that in order to create a depreciation successfully, the central bank also has to rely on the expectations channel. That is, the present paper implies that aggressive monetary-base expansion proposed by Orphanides and Wieland (2000) may be effective, but only if the central bank can make a credible promise to keep injecting liquidity into the economy going forward even when the deflationary pressure begins to subside. According to the analysis in this paper, by expanding the monetary base, but on a discretionary basis, and thereby only relying on the portfoliobalance effect, the central bank may not be able to generate a depreciation.

It should be noted that this paper focuses on exchange-rate policy under the regime of floating exchange rates, which has become most prevalent among industrialized as well as emerging-market countries. This differs from McCallum (2002), who proposes using the exchange rate as the policy instrument when the nominal interest rate is constrained at zero. In particular, McCallum recommends setting the exchange rate in response to inflation and the output gap, in the same way as a Taylor-type interest rate rule. By committing to a rule with the exchange rate as the instrument, McCallum's proposal requires that the central bank can control its exchange rate directly and thus can achieve any desired exchange rates in real time. One way to implement McCallum's proposal is to adopt a crawling peg whereby the exchange rate is adjusted in every period to respond to inflation and the output gap. The present paper, on the other hand, examines scenarios in which countries operate under floating exchange rates. The policy recommendations in the present paper do not require countries to make a switch to fixed exchange rates.

Finally, all the papers mentioned focus on the scenario in which the nominal 
interest rate has been constrained at zero for some time. The policy objective of the central bank is to escape from the liquidity trap at the earliest. This does not necessarily correspond to the conventional central bank policy objective of minimizing the volatility in inflation and the output gap. In a nutshell, all the paper mentioned attempted to apply their analysis to the economic experience of Japan prior to 2006. This is appropriate given that these papers do not rely on a fully dynamic framework with the standard conditions of uncertainty and rational expectations.

The present paper, on the other hand, imposes the standard conditions of uncertainty and rational expectations on a DSGE model and recognizing an explicit lower bound on interest rates. This setup can be used to study, not only the economic experience of Japan prior to 2006, but also the situation in which interest rates are low but still positive and may fall to zero if the economy is hit by sufficiently large contractionary shocks. Some particularly interesting scenarios of this characteristic are those in several Asian economies and in Japan after 2006. Thus, the present paper studies the conduct of monetary policy under the standard policy objective of minimizing the volatility of inflation and the output gap, specifically in circumstances where interest rates are unusually low.

In subsequent research, I hope to consider several extensions to the work so far:

First, the analysis in this paper is based on a calibrated model. The model parameters are calibrated such that we can capture the episode of low interest rates in the Far East, a phenomenon that has occurred only recently. When more data become available, the model can instead be estimated by a more sophisticated technique.

Second, after we develop algorithms that can be more effective in dealing with the curse of dimensionality, we can incorporate additional imperfections, such as incomplete exchange rate pass-through or imperfect capital mobility, into the model. This will allow us to study the interactions between these imperfections and the effectiveness of the exchange-rate channel.

Finally, under the commitment equilibrium, it is assumed that the central bank can make a credible promise that will constrain its action in the future. An important topic for future research is how to implement the commitment equilibrium. In other words, how can we design a mechanism that induces the central bank to deliver its own promise made from the past and thereby makes its promise credible among private agents.

\section{References}

[1] Adam, K., Billi, R., 2006. Optimal monetary policy under commitment with a zero bound on nominal interest rates. Journal of Money, Credit and Banking 38, 1877-1905. 
[2] Adam, K., Billi, R., 2007. discretionary monetary policy and the zero lower bound on nominal interest rates. Journal of Monetary Economics 54, 728752 .

[3] Ball, L., 1999. Policy rules for open economies. In: Taylor, J. B. (Ed.). Monetary policy rules. Chicago: University of Chicago Press, 127-144.

[4] Calvo, G. A., 1983. Staggered Prices in a Utility-Maximizing Framework. Journal of Monetary Economics 12, 383-398.

[5] Coenen, G., Wieland, V., 2003. The zero-interest rate bound and the role of the exchange rate for monetary policy in Japan. Journal of Monetary Economics 50, 1071-1101.

[6] Coenen, G., Wieland, V., 2004. Exchange-rate policy and the zero bound on nominal interest rates. American Economic Review 94, 80-84.

[7] Economic Intelligence Unit, 2007a. Country Report: Thailand. London: Economic Intelligence Unit.

[8] Edwards, S., 2006. The relationship between exchange rates and inflation targeting revisited. Working paper No. 12163. NBER.

[9] Edwards, S., Yeyati, E. L., 2005. Flexible exchange rates as shock absorbers. European Economic Review 49, 2079-2105.

[10] Gali, J., Monacelli, T., 2004. Monetary policy and exchange rate volatility in a small open economy. Review of Economic Studies 72, 707-734.

[11] Judd, K. L., 1998. Numerical Methods in Economics. Cambridge: MIT Press.

[12] Laxton, D., Isard, P., Faruqee, H., Prasad, E., Turtelboom, B., 1998. MULTIMOD Mark III: The core dynamic and steady-state levels. Occasional paper No. 164. IMF.

[13] Mohanty, M. S., Turner P., 2006. Foreign exchange reserve accumulation in emerging markets: what are the domestic implications? BIS Quarterly Review, September, 39-52.

[14] McCallum, B. T., 2000. Theoretical analysis regarding a zero lower bound on nominal interest rates. Journal of Money, Credit and Banking 32, 870904.

[15] McCallum, B. T., 2002. Inflation targeting and the liquidity trap. In: Loayza, N., Soto, R. (Eds.). Inflation Targeting: Design, Performance, Challenges. Santiago: Central Bank of Chile, 395-437.

[16] McKinnon, R. I., 1999. Comments on 'Monetary policy and zero inflation'. Monetary and Economic Studies 17, 183-188. 
[17] Meltzer, A. H., 1999. Monetary policy at zero inflation. Working paper. Carnegie Mellon University.

[18] Miranda, M. J., Fackler, P. L., 2002. Applied Computational Economics and Finance. Cambridge: MIT Press.

[19] Orphanides, A., Wieland, V., 2000. Efficient monetary policy design near price stability. Journal of the Japanese and International Economies 14, 327-365.

[20] Rudebusch, G. D., Svensson, L. E. O., 1999. Policy rules for inflation targeting. In: Taylor, J. B. (Ed.). Monetary policy rules. Chicago: University of Chicago Press, 203-246.

[21] Summers, L., 1991. Panel discussion: Price stability: How should long-term monetary policy be determined. Journal of Money, Credit and Banking 23, 625-631.

[22] Svensson, L. E. O., 2001. The zero bound in an open economy: A foolproof way of escaping from a liquidity trap. Monetary and Economic Studies 19, $277-312$.

[23] Svensson, L. E. O., 2004. The magic of the exchange rate: Optimal escape from a liquidity trap in small and large open economies. Working paper. Princeton University.

[24] Svensson, L. E. O., 2006. Optimization under commitment and discretion, and targeting rules and instrument rules. Lecture notes. Princeton University.

[25] Svensson, L. E. O., Woodford, M. 2005. Implementing optimal policy through inflation-forecast targeting. In: Bernanke, B., Woodford, M. (Eds.). The Inflation-Targeting Debate. Chicago: University of Chicago Press, 19-91.

[26] Taylor, J. B., 2001. The role of the exchange rate in monetary policy rules. American Economic Review 91, 263-267.

[27] US Treasury Department, 2006. Report to Congress on International Economic and Exchange Rate Policies, May. 